\title{
Dissolution of ground basalt and its effect on oxisol chemical properties and cocoa growth
}

\begin{abstract}
Obtaining suitable and environmentally sound materials for restoring properties of highly weathered soils (e.g., Oxisols) presents a great challenge. A study was carried out to: (i) determine the ability of ground basalt to increase the negative charge of an Oxisol, increase plant nutrients ( $\mathrm{Ca}, \mathrm{Mg}, \mathrm{K}$, and $\mathrm{Na}$ ), and suppress $\mathrm{Al}$ toxicity; and (ii) assess the effects of basalt application on cocoa growth. Pots containing $20 \mathrm{~kg}$ pot of Oxisol were treated with various rates of finely ground basalt $(<250 \mu \mathrm{m})$ and planted with cocoa (Theobroma cacao L.) in a greenhouse for 15 months. The soils and in situ soil solutions were sampled and analyzed periodically. The ground basalt continuously increased soil $\mathrm{pH}$ with increasing application rates. The cation exchange capacity occupied by base cations increased with increasing $\Delta \mathrm{pH}$ value (soil $\mathrm{pH}$ - $\mathrm{pH}$ ), confirming that the type of charge generation depends mainly on variable charge. The cation exchange capacity occupied by base cations value for different basalt rates at any given similar equilibrium $\mathrm{pH}$ value always increased with increasing basalt rates, suggesting that every increment of basalt rates generated "new negative sites" to retain cations in the soil. Basalt application continuously released base cations, as revealed by the significant increases in $\mathrm{Ca}, \mathrm{Mg}, \mathrm{K}$, and $\mathrm{Na}$ both in the forms of exchangeable cations and soluble cations (in situ solution), with concomitant suppression of toxic elements ( $\mathrm{Al}$ and $\mathrm{Mn}$ ). Basalt application significantly improved cocoa growth, suggesting that basalt is a promising material to be used for restoring the chemical properties of highly weathered tropical soils.
\end{abstract}

Keyword: basalt, chemical property, cocoa, dissolution, ion exchange, nutrition, Oxisol, $\mathrm{pH}$ 